\title{
Investigating the insiders' perspectives about dynamic assessment process and practicality
}

\author{
Adokh, Hadi
}

English Department, Faculty of Humanities, Najafabad Branch, Islamic Azad University, Najafabad, Iran (hadi.adokh@yahoo.com)

\section{Rafiee, Marzieh $\square$}

English Department, Faculty of Humanities, Najafabad Branch, Islamic Azad University, Najafabad, Iran (rafieemarzieh@gmail.com)

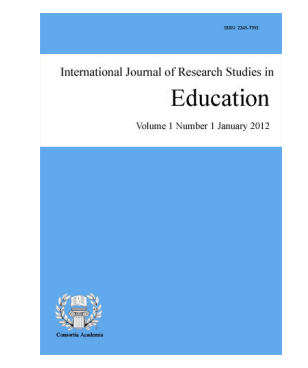

ISSN: 2243-7703 Online ISSN: 2243-7711

OPEN ACCESS

$\begin{array}{lll}\text { Received: } 17 \text { May } 2016 & \text { Revised: } 1 \text { August } 2016 & \text { Accepted: } 10 \text { August } 2016\end{array}$

Available Online: 17 August 2016 DOI: $10.5861 /$ ijrse.2016.1533

\section{Abstract}

This study is an attempt to provide an understanding of insiders' perspectives, EFL learners and teachers, about the process and practicality of dynamic assessment in the educational setting of Iran. Regarding these aims in mind, the participants, 25 EFL teachers, were required to fill out two questionnaires. Forty-five EFL learners were also asked to answer to a survey questionnaire, after a process of DA interventionist model while participants were instructed to write an essay. The results revealed that student participants had positive opinions towards DA in the language classrooms, though their views were not strongly positive. The analyzed teachers' questionnaire data indicated that teachers mostly believed that the DA practicality in Iranian English classroom was low. Implications and suggestions for further research were also offered.

Keywords: dynamic assessment; Zone of Proximal Development; interventionist approach; mediation; insider perspectives 


\section{Investigating the insiders' perspectives about dynamic assessment process and practicality}

\section{Introduction}

In recent years, the essential beliefs, concepts, and practices in second language assessment have changed, partly, due to the changing and transferring relationship between assessment and teaching. As pointed by Chapelle and Brindley (2002, p. 284), in 1970s, "assessment tended to take the form of proficiency testing, based on general ability constructs, which was largely unconnected to the curriculum". They argued that prevailing approaches to testing and assessment highlight the need for close relationship between the desired outcomes of curriculum, instruction, content, and assessment and this new focus also is reflected in current assessment methods, policies, and materials.

Two purposes for assessing were identified in the literature: summative and formative. Bachman (1990) explained that summative assessments (SA), which typically occur at the end of an instructional course, aim to capture the outcomes of instruction. In spite of the fact that SAs are concerned with products of previous and past learning, in reality, they are often applied to make decisions about individuals' future status. In contrast, Bachman believed that formative assessments (FA) are administered before completion of an educational period. Regarding their nature, FAs have a much closer relationship to instruction because their outcomes give direct feedback to classroom teaching.

Despite the advantages of FA practices, there have been some major concerns over their efficiency and effectiveness in improving learning. In order for FA practices to be more efficient in learning, practitioners suggest that instruction and assessment practices need to be harmonized and integrated (Branden, 1994). However, some critics believe that this expectation is not realized. Specifically, Lantolf and Poehner (2005) disputed that in most FA situations, assessment and instruction remain two separate items. Similarly, Torrance and Pryor (1998) contended that language teachers have little understanding and information of the relationship between assessment and learning and there is no actual intervention and mediation in the developmental process of the learners in most classroom-based FA situations and practices. As a consequence, Grigorenko and Stenberg (2002) called for a paradigm shift in the practices and implementation process of FA to combine instruction and assessment as a unified practice.

Nowadays, critics recommend educators to use multiple assessments in order to evaluate whether learning goals have been achieved or not. Dynamic assessment (DA) is a kind of interactive and integrative assessment recently used in education. It is the product of the research conducted by Vygotsky, a developmental psychologist. Vygotsky (1978, p. 53) believed that "the normal learning situation for a learner is a socially meaningful cooperative activity". This interpersonal interaction can be regarded as the initiator of new learning abilities and cognitive functions. As the time passes, they are transformed and internalized and lastly, settle the learner's inner cognitive processes. Relatively, DA is a new and advanced approach to L2 assessment that has been recommended to L2 research and educational settings by Lantolf and Poehner (2004) and Poehner and Lantolf (2005).

With respect to this line of inquiry, and regarding the fact that in recent years there has been a growing interest among Iranian researchers to evaluate the role of DA and its influence on different components of foreign language teaching (Birjandi \& Daftarifard, 2011; Eslami-Rasekh \& Mardani, 2010; Pishghadam, Barabadi, \& Mehri Kamrood, 2011), the current study tried to investigate to what extent Iranian EFL teachers believe DA is practical in Iranian EFL context. Furthermore, students' perceptions of the process of DA applied in the classroom were measured. The study, specifically, seeks to find answer to the following questions: 
$>\quad$ What are student perceptions of the DA process?

$>$ To what extent do Iranian EFL teachers believe DA is practical in Iranian EFL context?

\section{Methodology}

\subsection{Participants}

25 experienced teachers in the English as a Foreign Language (EFL) classes agreed to participate in this project. The teachers were chosen based on their knowledge about the concepts of DA and self-esteem, teaching experience, and willingness to participate in a research study. All of the teachers were familiar with the concept of DA and self-esteem in their fields of study and working. All of these teachers were working in private English institutes in Najafabad. They had graduated from the field of TEFL (Teaching English as a Foreign Language), or earned a master's in a TEFL-related field). Regarding their language proficiency, the teachers varied: four of them had passed their TOFEL or IELTS in recent years, nine of them were enrolling in pre-IELTS and pre-TOFEL courses in other language institutes and twelve of them were recently graduated from their universities in MA major. Besides teachers, 45 English learners were selected from among male and female undergraduate university students. The mean age of the participants was 22 and none had studied the English language abroad. They could use and understand English acceptably.

\subsection{Instruments}

In order to measure the language learners' perceptions of the process of DA in language classrooms, a perception questionnaire (Mahmoud Fahmy, 2013) was applied. This survey included nine statements, and students were required to respond to each one by selecting one of five choices: strongly disagree, disagree, I do not mind it/similar to regular instruction, agree, or strongly disagree. The internal consistency reliability (Cronbach's alpha) for the different proficiency levels were .88 and the questionnaire was reported to have high content and face validity (Mahmoud Fahmy, 2013).

In order to explore the English teachers' perceptions about the practicality of DA in Iranian EFL context, a perception questionnaire, which was designed by Eshaghi Sardrood (2011), was applied. The questionnaire consisted of 15 five-point Likert-type items. The content validity of the questionnaire was first sought through a review of related literature (Poehner, 2008) and then it was piloted in a group of English language teachers (Eshaghi Sardrood, 2011). The reliability index of the questionnaire was reported to be 0.79 by using Cronbach' Alpha Coefficient.

\subsection{Data collection procedure}

In order to tap the teacher participants' perceptions of DA practicality in Iranian EFL setting, the teacher were required to fill out the perception questionnaire. Though the teacher participants all admitted that they were familiar with DA concepts, before administering the questionnaire, the teachers were asked to take part in a session in which the researcher thoroughly explained the concept to them.

To explore the learners' perception about the DA process, they were provided with a set of topics of their interest, already tapped by the researcher. They were asked to write an essay with a topic of their interest. Following Lantolf and Poehner's (2004) interventionist model, participants composed the essay while they were provided with preplanned mediation. To provide participants with preplanned mediation, Lantolf and Poehner's (2011) scale was adopted, on the basis of which 8 forms of mediation was provided depending on each and every particular learner's responsiveness. They are as follows: 1 . Teacher pauses, 2 . Teacher repeats the whole phrase questioningly, 3. Teacher repeats just the error part of the sentence, 4 . Teacher asks a question, for example: what is wrong with this sentence? 5. Teacher points out the incorrect word, 6. Teacher asks either...or... questions, 7. 
Adokh, H., \& Rafiee, M.

Teacher identifies the correct answer, and 8. Teacher explains why.

The researcher focused on three main composition criteria, namely, lexical, grammatical, and coherence. If a learner's response was correct, the mediator i.e. the researcher would give no mediation. However, if the learner's response were not correct and/or appropriate, the mediator would move one or more steps further till the last step where s/he would manage to provide the learner with full explanations. In fact, the forms of mediation given would be as follows: 1 . Teacher pauses, 2 . Teacher repeat the whole phrase questioningly, and 3 . Teacher repeats just the part of the sentence with the error. This procedure continued for 10 sessions. In the last session, perception questionnaire was administered.

\section{Data analysis and results}

Table 1 below shows the language learners' responses to the perception survey questionnaire. As the percentages of the language learners' responses to the questionnaire show, students mostly have positive view towards DA, though their opinions were partially positive about DA process.

\section{Table 1}

Language learners' perceptions about DA process

\begin{tabular}{|c|c|c|c|c|c|c|}
\hline No & Scales & 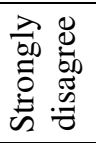 & 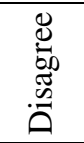 & 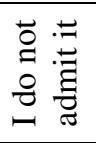 & 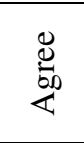 & 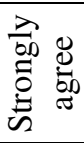 \\
\hline 1 & $\begin{array}{l}\text { The DA instruction method is an effective classroom } \\
\text { approach for language learning }\end{array}$ & $4 \%$ & $9 \%$ & $10 \%$ & $37 \%$ & $40 \%$ \\
\hline 2 & $\begin{array}{l}\text { DA instruction is capable of diagnosing each student's } \\
\text { language needs on a daily basis. }\end{array}$ & $2 \%$ & $8 \%$ & $5 \%$ & $30 \%$ & $55 \%$ \\
\hline 3 & $\begin{array}{l}\text { The hinting process helped me overcome my personal } \\
\text { language difficulties. }\end{array}$ & $8 \%$ & $20 \%$ & $6 \%$ & $42 \%$ & $30 \%$ \\
\hline 4 & $\begin{array}{l}\text { The hinting process that I experienced improved my ability } \\
\text { in English quickly. }\end{array}$ & $9 \%$ & $11 \%$ & $5 \%$ & $32 \%$ & $43 \%$ \\
\hline 5 & $\begin{array}{l}\text { I would recommend DA instruction for other language } \\
\text { students. }\end{array}$ & $7 \%$ & $20 \%$ & $2 \%$ & $42 \%$ & $31 \%$ \\
\hline 6 & $\begin{array}{l}\text { Knowing the DA standards helped me understand what I } \\
\text { need to do to improve my language abilities. }\end{array}$ & $14 \%$ & $25 \%$ & $1 \%$ & $28 \%$ & $32 \%$ \\
\hline 7 & $\begin{array}{l}\text { Collaborating with other students to deliver a measurable } \\
\text { product provided me with a great learning environment. }\end{array}$ & $5 \%$ & $9 \%$ & $8 \%$ & $40 \%$ & $38 \%$ \\
\hline 8 & $\begin{array}{l}\text { Following other students going through the hinting process } \\
\text { helped me learning and or overcoming my own personal } \\
\text { difficulties. }\end{array}$ & $14 \%$ & $22 \%$ & $2 \%$ & $27 \%$ & $35 \%$ \\
\hline 9 & $\begin{array}{l}\text { Using DA instruction in the classroom was practical and } \\
\text { enjoyable. }\end{array}$ & $6 \%$ & $14 \%$ & $1 \%$ & $24 \%$ & $55 \%$ \\
\hline
\end{tabular}

The second research question was formed in order to examine the EFL teachers' perceptions of practicality of DA in Iranian context. The percentages of the participants' responses are shown in Table 2. As the table shows, teachers almost believed that the probability of DA practicality in Iranian English classroom was low. With the exception of some cases, such as "providing implicit to explicit standardized feedback", "managing the time to interact and work with every individual student" and "managing the time to integrate teaching with assessment", in which teachers believed that DA can be practiced in the classrooms, in other cases teachers believed that there was only a partial or limited implementation of DA. Overall, the teachers' attitudes towards the practicality of DA were negative. 
Table 2

Teacher participants' perceptions of DA practicality

\begin{tabular}{|c|c|c|c|c|c|c|}
\hline No & Degree of DA practicality in your classroom & 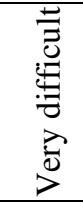 & 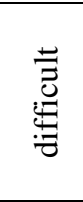 & 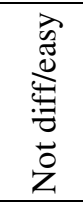 & $\widehat{\grave{\Xi}}$ & $\begin{array}{l}\overrightarrow{0} \\
\overrightarrow{0} \\
\overrightarrow{0} \\
\overrightarrow{0} \\
\overrightarrow{0}\end{array}$ \\
\hline 1 & The application of pre-test teach post-test model & $30 \%$ & $43 \%$ & $12 \%$ & $11 \%$ & $4 \%$ \\
\hline 2 & $\begin{array}{l}\text { Identifying every students' ability level of English before } \\
\text { teaching }\end{array}$ & $20 \%$ & $52 \%$ & $20 \%$ & $3 \%$ & $5 \%$ \\
\hline 3 & $\begin{array}{l}\text { Identifying every students' needs, goals and learning } \\
\text { problems before teaching }\end{array}$ & $43 \%$ & $37 \%$ & $10 \%$ & $8 \%$ & $2 \%$ \\
\hline 4 & $\begin{array}{l}\text { Preparing graduated (easy to difficult) activities and tasks } \\
\text { before teaching }\end{array}$ & $52 \%$ & $28 \%$ & $8 \%$ & $8 \%$ & $4 \%$ \\
\hline 5 & Providing implicit to explicit standardized feedback & $13 \%$ & $26 \%$ & $16 \%$ & $35 \%$ & $10 \%$ \\
\hline 6 & $\begin{array}{l}\text { Recording the amount and kind of feedback (assistance) } \\
\text { for every individual student }\end{array}$ & $47 \%$ & $37 \%$ & $6 \%$ & $9 \%$ & $1 \%$ \\
\hline 7 & Getting continuous feedback about students' progress & $49 \%$ & $34 \%$ & $14 \%$ & $1 \%$ & $2 \%$ \\
\hline 8 & Adapting teaching to the students responsiveness & $44 \%$ & $32 \%$ & $12 \%$ & $7 \%$ & $5 \%$ \\
\hline 9 & $\begin{array}{l}\text { Managing the time to interact and work with every } \\
\text { individual student }\end{array}$ & $17 \%$ & $25 \%$ & $8 \%$ & $32 \%$ & $18 \%$ \\
\hline 10 & Managing the time to integrate teaching with assessment & $22 \%$ & $29 \%$ & $1 \%$ & $39 \%$ & $9 \%$ \\
\hline 11 & $\begin{array}{l}\text { Managing the available resources such as pair-work, } \\
\text { group work etc. to have students help each other }\end{array}$ & $37 \%$ & $52 \%$ & $6 \%$ & $3 \%$ & $2 \%$ \\
\hline 12 & $\begin{array}{l}\text { Utilize the computer-assisted instruction and other } \\
\text { technological tools in scaffolding students }\end{array}$ & $37 \%$ & $46 \%$ & $10 \%$ & $5 \%$ & $2 \%$ \\
\hline 13 & Determining students' learning potential & $38 \%$ & $45 \%$ & $8 \%$ & $6 \%$ & $3 \%$ \\
\hline 14 & $\begin{array}{l}\text { Passing or failing of the students on the basis of DA } \\
\text { results }\end{array}$ & $45 \%$ & $37 \%$ & $10 \%$ & $4 \%$ & $4 \%$ \\
\hline 15 & Replacing the current practice of static tests with DA & $61 \%$ & $30 \%$ & $2 \%$ & $5 \%$ & $2 \%$ \\
\hline
\end{tabular}

\section{Discussion of findings}

The results of students' perception questionnaire revealed that student participants had positive opinions and views towards DA in the language classrooms. Though they showed to have positive perceptions, their responses towards the questionnaire statements, which were all positive statements about the DA instruction and all its relevant activities and topics, were not strongly positive. This finding contradicted what Mahmoud Fahmy (2013) found in his research where there was only one exception in the participants' responses in the questionnaire who selected "I do not mind it" item and all the participants' chose "agree" and "strongly agree".

As regards the teachers' perception towards the practicality of DA in Iranian setting, the analyzed data revealed that teachers mostly believed that the DA practicality in Iranian English classroom was low. Excepted three items in the questionnaire, in which teachers selected high practicality of DA in English classrooms; other items were mostly rated as low probability of DA practicality in language classrooms.

One reason for the students and teachers' finding might be that DA, as mentioned by Eshaghi Sardood (2011), DA is not fully worked out in the Iranian educational setting. Relying on the Kumaravadivelu (2003) three parameters of "particularity", "practicality" and "possibility", Eshaghi Sardood (2011) contends that any attempt to implement DA in the classrooms should take the following points into consideration: First, with respect to the "particularity" parameter, the context in which DA is to be practiced should be thoroughly studied. As Kumaravadivelu (2003, p. 34) asserted, "any language pedagogy to be relevant must be sensitive to a particular group of teachers teaching a particular group of learners pursuing a particular set of goals within a particular institutional context". In most Iranian EFL classrooms, regarding this parameter, the number of students is more than standards and teachers still adhere to the conventional approach of assessment, such as multiple-choice or essay-type exams (Nazari, 2012); in fact, teachers are not instructed enough to work out DA particularly in this 
EFL context.

According to the practicality parameter, a method should be applicable in real context; otherwise, the relationship between practice and theory cannot be established. This parameter argues against the existing views in applied linguistics, in which language teachers are regarded to be spoon-fed with a pool pf knowledge and the theories theorists produce (Kumaravadivelu, 2003). As regards the role of Iranian EFL teachers in language classrooms, often the dominant society of Iran influences the educational setting, which eventually leads to ignoring the teachers' sense of soundness and plausibility (Eshaghi Sardood, 2011). Iranian EFL teachers are working in a situation in which some pre-determined set of materials and methods are dictated to them to be implemented in the classrooms. However, this restricted view of language teaching methodology is mostly limited to state classrooms and in private language institutes, teachers have more freedom to decide on the appropriate methodology and materials to be applied in the classrooms.

On the basis of possibility parameter, Kumaravadivelu (2006) stresses on enhancing the teachers and students' critical thinking in order to question the status quo of educational context. This principle, furthermore, focuses on the factors including the experience teachers bring to the classrooms, their backgrounds including culture, race, education, language and other variable which directly or indirectly affect the classroom input and interactions. In spite of the fact that the trend of critical thinking is gaining momentum in Iranian EFL context so that practitioners can evaluate the current method of teaching and assessments, it has a relatively slow movement (Hashemi, Behrooznia \& Mohaghegh, 2014). More specifically, Iranian EFL teachers cannot provide the existing educational context with a radical change in traditional testing and teaching situations. Moreover, as pointed out by Eshaghi Sardood (2011), there is not much tendency in this context to match with the movement of current paradigm shift in ELT and replace the status quo with DA or any other alternative assessment and teaching tools.

\subsection{Implications and suggestions for further research}

The findings of this study can have several pedagogical implications for language teachers, language learners, and curriculum designers. Applying DA, language teachers can create a learning environment, which is free of stress, and therefore results in positive wash-back effect during exam times, since DA provides a learning environment in which teaching and assessment goals and practices are in line and interwoven with each other. DA assists EFL learners to take the advantage of mediation provided by the teachers and become autonomous in the language classroom and in doing similar language learning tasks later on. Finally, language learners can take the advantages of syllabuses which apply DA technique. Curriculum and material designers can develop syllabuses which benefit DA as a teaching technique.

Although every possible effort was made to avoid research design flaws of previous research studies, this study cannot claim to be totally free from limitations. This section foregrounds a few of these limitations. One limitation of the study was placed on the way data was gathered. As mentioned before, the main instruments applied in data collection process were two questionnaires. Though this data collection instrument brought about enriched results, the inclusion of other methods, including interviews, participants' note talking, and other methods of data collection could make the research more comprehensive.

This study suffered from limited number of participants (a number of 50 EFL learners). Although the study provided a clear picture of the influence of self-concept and OCSs on the participants' oral performance, the limited number of participants who agreed to take part in the data collection procedure of this study imposed further limitation to this research project. Future studies can be carried out with more numbers of participants. Greater and more active participations of teachers and language learners more likely result in better understanding of the pedagogical practices DA. 


\section{References}

Bachman, L. F. (1990). Fundamental considerations in language testing. Oxford: Oxford University Press.

Birjandi, P., \& Daftarifard, P. (2011). The role of ZPD in estimating learners' future level of development: The case of reading ability. Journal of English Studies, 1(2), 63-78.

Branden, N. (1994). The six pillars of self-esteem. New York: Bantam Books.

Chappelle, C., \& Brindley, G. (2002). Assessment. In N. Schmitt (Ed.), Introduction to applied linguistics (pp. 267-288). New York, NY: Hodder Arnold.

Eshaghi Sardood, J. (2011). Dynamic assessment in Iranian EFL classrooms: A ost- method enquiry. The Journal of Applied Linguistics, 4(2), 47-63.

Eslami-Rasekh, A., \& Mardani, M. (2010). Investigating the effects of teaching apology speech act, with a focus on intensifying strategies, on pragmatic development of EFL learners: The Iranian context. Journal of Language Society and Culture, 30, 96-103.

Grigorenko, E. L., \& Sternberg, R. J. (2002). Dynamic testing: The nature and measurement of learning poetential. Cambridge, UK: Cambridge University.

Hashemi, M. R., Behrooznia, S., \& Mohaghegh Mahjoob, F. (2014). A critical look into Iranian EFL university students' critical thinking and argumentative writing. Iranian Journal of Applied Linguistics, 17(1), 71-92.

Kumaravadivelu, B. (2003). Critical language pedagogy: a postmethod perspective on English language teaching. World Englishes, 22(4), 539-550. http://dx.doi.org/10.1111/j.1467-971X.2003.00317.x

Kumaravadivelu, B. (2006). TESOL methods: changing tracks, challenging trends. TESOL Quarterly, 40, 59-81. http://dx.doi.org/10.2307/40264511

Lantolf, J. P., \& Poehner, M. E. (2004). Dynamic assessment: Bridging the past into the future. Journal of Applied Linguistics, 1(1), 49-74. http://dx.doi.org/10.1558/japl.1.1.49.55872

Lantolf, J. P., \& Poehner, M. E. (2011). Dynamic assessment in the classroom:Vygotskian praxis for second language development. Language Teaching Research, 15(1), 11-33. http://dx.doi.org/10.1177/1362168810383328

Mahmoud Fahmy, M. (2013). The effect of dynamic assessment on adult learners of Arabic: A mixed-method study at the defense language institute foreign language center (Doctoral dissertation). University of San Francisco, San Francisco, CA.

Nazari, B. (2012). Test to teach instructionof dynamic assessment: A critical overview. Belletera Journal of Teaching and Learning Language and Literature, 5(4), 56-68.

Pishghadam, R., Barabadi, E., \& Mehri Kamrood, A. (2011). The differing effect of computerized dynamic assessment of L2 reading comprehension on high and low achievers. Journal of Language Teaching and Research, 2(6), 1353-1358. http://dx.doi.org/10.4304/jltr.2.6.1353-1358

Poehner, M. E. (2008). Dynamic assessment: A Vygotskian approach to understanding and promoting second language development. Berlin: Springer. http://dx.doi.org/10.1007/978-0-387-75775-9

Torrance, H., \& Pryor, J. (1998). Investigating formative assessment: Teaching, learning and assessment in the classroom. Maidenhead: Open University Press.

Vygotsky, L. (1978). Mind in society: The development of higher psychological process. Cambridge: MA: Harvard University Press. 
Adokh, H., \& Rafiee, M. 